\section{Should Hospital Pharmacists Prescribe?}

\section{THE "PRO" SIDE}

Should hospital pharmacists be prescribing medications? This question reminds me of the age-old record player in my cabin, which keeps playing the same song over and over. Although in the past this question has been debated numerous times, recent changes to our practice landscape may finally help us to answer this question once and for all.

Formerly recognized mainly for distributive functions, pharmacists in all settings are now involved in health promotion, disease-state management, and pharmaceutical care, as well as both collaborative and independent prescribing. As our roles have evolved to become more clinically focused, prescribing has become a logical extension of the provision of comprehensive pharmaceutical care. ${ }^{1}$ Hospital pharmacists have a long history of being leaders in prescribing, such as in pharmacokinetic dosing services, anticoagulation management, and therapeutic interchange programs. So, when the question is asked, "Should hospital pharmacists prescribe?" the answer is obvious! We have been doing it for decades.

While not an entirely new concept, prescribing by hospital pharmacists has continued to expand in recent years. According to the 2011/2012 Hospital Pharmacy in Canada survey, 55\% of responding hospitals indicated that pharmacist prescribing existed in their institutions. ${ }^{2}$ An increase in independent prescribing activities (as opposed to independent prescribing) was also noted, relative to previous years. For instance, in the 2007/2008 survey, about a quarter $(24 \%)$ of respondents reported having independent prescribing rights for dosage adjustments, and the proportion doubled, to $48 \%$, in the $2011 / 2012$ survey. ${ }^{2,3}$ The trend for increasing prescribing by pharmacists is likely to continue, given changes to the legal framework that are occurring across Canada. Alberta was the first province to grant pharmacists prescribing privileges (in 2007), and currently all provinces have some form of expanded scope-of-practice legislation in place ${ }^{4}$ and are at various stages of obtaining prescriptive authority.

Support for pharmacist prescribing is echoed by our national pharmacy societies, which continue to advocate for prescriptive authority. For example, the Blueprint for Pharmacy envisions that pharmacists will "initiate, modify and continue drug therapy and order tests". ${ }^{4}$ The Position Statement on Pharmacist Prescribing of the Canadian Pharmacists Association states that "pharmacists will take on increased accountability for patient-centred, outcomes focused care", 5 and the Canadian Society of Hospital Pharmacists "advocates the role of pharmacists as capable prescribers and supports the pharmacist's role in a collaborative prescribing model". ${ }^{6}$ These views are not limited to Canada. ${ }^{7}$ The 2008 Basel Statements, reflecting the perceptions of pharmacists from 98 countries, acknowledged the benefits of allowing hospital pharmacists to prescribe. ${ }^{8}$

Clearly, support for prescribing by hospital pharmacists is growing, so what is the impetus for this trend? In an era of rising health care costs, pharmacists have been referred to as an underutilized health care system resource. ${ }^{9}$ Traditionally, pharmacists' interventions have been retrospective in nature, ${ }^{7}$ representing reactions to drug-related problems after they have occurred. Often, however, the most cost-effective therapy focuses on prevention, including avoiding drug-related problems. ${ }^{10}$ For instance, the "9000 Points of Care" plan, developed by the Canadian Association of Chain Drug Stores, has estimated that allowing pharmacists to proactively treat minor ailments and administer vaccines would prevent up to 600000 visits to the emergency department and 1500 hospital admissions and would free up 2.4 million physician hours. ${ }^{11}$ In essence, expanding the professional scope of pharmacists to include prescribing might help to address some of the significant challenges in health care, including safety, medication costs, and access to care.

To support these claims, the positive impact of including a pharmacist on clinical teams is well established. ${ }^{12}$ For instance, in one study, a $78 \%$ reduction in drug errors was noted after a pharmacist became involved in routine medical rounds, ${ }^{13}$ and in another, US\$270 000 (1995 dollars) was saved annually by including a pharmacist in physician rounds in an intensive care unit. $^{14}$ The provision of pharmaceutical care facilitated by prescriptive agreements or protocols has improved therapeutic outcomes in clinical areas such as anticoagulation, heart failure, dyslipidemia, hypertension, and diabetes mellitus, as well as antibiotic and thromboembolic prophylaxis. ${ }^{14-25}$ For example, a pharmacist-managed heart failure titration clinic increased the proportion of patients receiving appropriate pharmacotherapy, ${ }^{15}$ and a pharmacist-managed anticoagulation monitoring service reduced the risk of associated complications relative to what occurred with usual care. ${ }^{16}$

Within the hospital, the nature of pharmacist prescribing will 
vary depending on provincial legislation, institutional policies, and the clinical situation. The prescriptive authority granted to hospital pharmacists does not translate into an obligation to prescribe, and the question of "whether or not to prescribe" may be dictated by circumstance. For instance, a pharmacist participating in medical rounds may be more inclined to provide clinical input by making a suggestion, given the direct accessibility of a physician team member. A pharmacist performing medication reconciliation, however, may find it appropriate to use prescriptive authority to correct a medication error immediately, rather than waiting for a cosignature to implement his or her suggestion. Taken in this context, prescribing by hospital pharmacists should be viewed as a tool that may be used as needed to assist in providing pharmaceutical care in the most efficient manner possible.

As is the case with all practice change affecting many disciplines, there will always be early adopters and those who are less convinced. The Canadian Medical Association and the American Medical Association have both expressed opposition to pharmacist prescribing. ${ }^{26,27}$ Perhaps the best way to convince these groups is to approach the issue from a grassroots level, by working collaboratively with our colleagues to demonstrate that our goal is to complement (not replace) the role of the physician. The argument that there is insufficient evidence to support improved outcomes for pharmacist prescribing should cease if we continue to produce sound scientific research in this area. In the meantime, we have a professional responsibility to work toward establishing a better health care system that could improve the outcomes and cost-effectiveness of drug therapy. ${ }^{6}$ It is simply not cost-effective to pay a pharmacist wage to track down a physician to fix an inpatient medication order or cosign a therapeutic substitution, when prescriptive authority could be used as an immediate solution—nor does it seem beneficial to the patient.

To conclude, the question of whether or not hospital pharmacists should prescribe has expired. Instead of spending our time debating it, we should spend more time tackling the hurdles and embracing the opportunities.

\section{References}

1. Pearson GJ. Evolution in the practice of pharmacy—not a revolution. CMAJ. 2007;176(9):1295-6.

2. Babich M, Bornstein C, Bussières JF, Doucette D, Hall KW, Lefebvre P, et al., editors. Hospital pharmacy in Canada 2011/2012 report. Eli Lilly; 2012 [cited 2014 May 20]. Available from: www.lillyhospitalsurvey.ca/hpc2/ content/rep_2012_toc.asp

3. Babich M, Bussières JF, Hall KW, Harding J, Johnson N, Lefebvre P, et al., editors. Hospital pharmacy in Canada 2007/2008 report. Eli Lilly; 2008 [cited 2014 Mar 20]. Available from: www.lillyhospitalsurvey.ca/hpc2/ content/rep_2008_toc.asp

4. Blueprint for Pharmacy Steering Committee. Blueprint for Pharmacy: our way forward. Ottawa (ON): Canadian Pharmacists Association; 2013 [cited 21May2014]. Available from http://blueprintforpharmacy.ca/docs/pdfs/ blueprint-priorities---our-way-forward-2013---june-2013.pdf

5. CPhA position statement on pharmacist prescribing. Ottawa $(\mathrm{ON})$ : Canadian Pharmacists Association; 2007 [revised 2011; cited 2014 May 23]. Available from: www.pharmacists.ca/cpha-ca/assets/File/cpha-on-theissues/PPPharmacistPrescribing.pdf
6. Task Force on Pharmacist Prescribing (Pearson G, Yuksel N, Card D, Chin T, Gray M, Hawbold J, et al.). Statement on pharmacist prescribing. Can J Hosp Pharm. 2002;55(1):55.

7. Emmerton L, Marriott J, Bessell T, Nissen L, Dean L. Pharmacists and prescribing rights: review of international developments. J Pharm Pharm Sci. 2005;8(2):217-25.

8. The Basel Statements on the future of hospital pharmacy. Am J Health Syst Pharm. 2009;66(5 Suppl 3):s61-6.

9. American Pharmacists Association Foundation and American Pharmacists Association. Consortium recommendations for advancing pharmacists' patient care services and collaborative practice agreements. J Am Pharm Assoc (2003). 2013;53(2):e132-41.

10. Viktil KK, Blix HS. The impact of clinical pharmacists on drug-related problems and clinical outcomes. Basic Clin Pharmacol Toxicol. 2008; 102(3):275-80.

11. 9000 points of care: improving access to affordable healthcare [website]. North York (ON): Canadian Association of Chain Drug Stores; 2013 Apr [cited 2014 May 30]. Available from: http://9000pointsofcare.ca/contactus/

12. Kaboli PJ, Hoth AB, McClimon BJ, Schnipper JL. Clinical pharmacists and inpatient medical care: a systematic review. Arch Intern Med. 2006;166(9):955-64.

13. Kucukarslan SN, Peters M, Mlynarek M, Nafziger DA. Pharmacists on rounding teams reduce preventable adverse drug events in hospital general medicine units. Arch Intern Med. 2003;163(17):2014-8.

14. Leape LL, Cullen DJ, Clapp MD, Burdick E, Demonaco HJ, Erickson JI, et al. Pharmacist participation on physician rounds and adverse drug events in the intensive care unit. JAMA. 1999;282(3):267-70.

15. Martinez AS, Saef J, Paszczuk A, Bhatt-Chugani H. Implementation of a pharmacist-managed heart failure medication titration clinic. Am J Health Syst Pharm. 2013;70(12):1070-6.

16. Hall D, Buchanan J, Helms B, Eberts M, Mark S, Manolis C, et al. Health care expenditures and therapeutic outcomes of a pharmacist-managed anticoagulation service versus usual medical care. Pharmacotherapy. 2011; 31(7):686-94.

17. Witt DM, Sadler AM, Shanahan RL, Mazzoli G, Tillman DJ. Effect of a centralized clinical pharmacy anticoagulation service on the outcomes of anticoagulation therapy. Chest. 2005;127(5):1515-22.

18. Cording MA, Engelbrecht-Zadvorny EB, Pettit BJ, Eastham JH, Sandoval R. Development of a pharmacist-managed lipid clinic. Ann Pharmacother. 2002;36(5):892-904.

19. Smith MC, Boldt AS, Walston CM, Zillich AJ. Effectiveness of a pharmacy care management program for veterans with dyslipidemia. Pharmacotherapy. 2013;33(7):736-43.

20. Magid DJ, Olson KL, Billups SJ, Wagner NM, Lyons EE, Kroner BA. A pharmacist-led, American Heart Association Heart360 Web-enabled home blood pressure monitoring program. Circ Cardiovasc Qual Outcomes. 2013;6(2):157-63.

21. Morgado MP, Morgado SR, Mendes LC, Pereira LJ, Castelo-Branco M. Pharmacist interventions to enhance blood pressure control and adherence to antihypertensive therapy: review and meta-analysis. Am J Health Syst Pharm. 2011;68(3):241-53.

22. Anaya JP, Rivera JO, Lawson K, Garcia J, Luna J Jr, Ortiz M. Evaluation of pharmacist-managed diabetes mellitus under a collaborative drug therapy agreement. Am J Health Syst Pharm. 2008;65(19):1841-5.

23. Taveira TH, Dooley AG, Cohen LB, Khatana SA, Wu WC. Pharmacistled group medical appointments for the management of type 2 diabetes with comorbid depression in older adults. Ann Pharmacother. 2011;45(11): 1346-55.

24. Brummel AR, Soliman AM, Carlson AM, de Oliveira DR. Optimal diabetes care outcomes following face-to-face medication therapy management services. Popul Health Manag. 2013;16(1):28-34.

25. Galindo C, Olivé M, Lacasa C, Martínez J, Roure C, Lladó M, et al. Pharmaceutical care: pharmacy involvement in prescribing in an acute-care hospital. Pharm World Sci. 2003;25(2):56-64.

26. e-Panel survey summary: pharmacist prescribing. Ottawa $(\mathrm{ON})$ : Canadian Medical Association; 2007 [cited 2014 May 23]. Available from: www.guidespratiqueclinique.ca/e-panel-pharmacist-prescribing, 
27. Weiss D. AMA opposes giving pharmacists prescription authority. Pharm Times. 2012 Jul 10 [cited 2014 May 23]. Available from: www.pharmacytimes.com/news/AMA-Opposes-Giving-Pharmacists-PrescriptionAuthority

\section{Holly Mansell, BSP, PharmD}

Assistant Professor

College of Pharmacy and Nutrition

University of Saskatchewan

Saskatoon, Saskatchewan

Competing interests: None declared.

\section{THE "CON" SIDE}

Over recent years, the way health care is delivered and by whom has been subject to continual change. This is a global phenomenon, especially in the developed world, and reflects changes in workforce, budgetary constraints, and demand. The evolution of prescribing rights is one example of such a change. Prescribing is no longer a unique privilege for medical doctors. For example, nurses and pharmacists have been able to prescribe to some degree in the United States since the 1970s. ${ }^{1}$ The first prescribing course for pharmacists in Scotland was offered in 2003..$^{2}$ This course initially covered supplementary prescribing, a format whereby pharmacists could prescribe within a set treatment plan that was discussed with a medical prescriber. After legislative changes that extended the rights of pharmacists and nurses in the United Kingdom, these health care professionals can now prescribe from the whole range of the British National Formulary without consulting a medical doctor. ${ }^{3}$ Nonmedical prescribing has been seen to maximize the skills and contributions of pharmacists within multidisciplinary teams. ${ }^{4}$ Canadian jurisdictions have started to expand pharmacists' prescribing rights over the past few years, and as of August 2010, pharmacist prescribing was possible in nearly all provinces. ${ }^{5}$

Despite the advantages of pharmacists prescribing in secondary care, there are disadvantages to independent pharmacist prescribing that must be considered carefully before this practice is implemented locally.

Currently, hospital pharmacists are well-respected members of multidisciplinary teams, often involved in ward rounds. Their traditional role has been that of a gatekeeper and safety-net provider. Prescriptions written by one member of the clinical team, usually a junior doctor, are reviewed by the pharmacist, either on the ward or at the point of dispensing. The pharmacist provides an independent review and opinion within the multidisciplinary team, from the pharmaceutical perspective, and supports clinical and cost-efficient decisions. This is all done from a therapeutic viewpoint rather than a diagnostic viewpoint. In the
UK, ward pharmacists review patients within $24 \mathrm{~h}$ of admission, reconcile their medications, and discuss any omissions or necessary changes with the medical team; additionally, they regularly review medical charts of all inpatients and check any new prescriptions for potential drug interactions or patient contraindications. At our local hospital, all discharge prescriptions also receive a clinical check by a ward pharmacist; otherwise, the prescription will not be dispensed by the hospital dispensary.

The following examples illustrate why we should be very cautious about destabilizing this effective system by introducing pharmacist prescribing.

Nissen ${ }^{6}$ stated that pharmacist prescribers would have to adhere to the same rules as medical prescribers, including review of their prescriptions by a nonprescribing pharmacist. Reflecting this statement, prescribing of medication and subsequent dispensing must be kept separate, ${ }^{6}$ and one implication of this approach is fragmentation of the pharmacy workforce into "prescribers" and "nonprescribers". ' A second implication is that a new system, and new resources, would be needed to deliver the gatekeeper and safety-net roles previously performed by the pharmacist. In practice, this rarely happens, perhaps because (in the UK and possibly elsewhere) pharmacists often take on prescribing at an individual practitioner level, operating within an area of special interest or expertise, rather than taking a strategic approach involving service redesign. ${ }^{8}$ This situation has potential risks for patient safety.

Secondly, I fear there will be a decline in bedside teaching of prescribing skills by pharmacists to medical doctors. Emmerton and others ${ }^{7}$ have highlighted that prescribing by pharmacists is more efficient, as it is no longer necessary to chase medical staff for amendments to prescriptions, because the pharmacists have the authorization to make these changes themselves. However, a significant downside is the loss of opportunities to educate medical prescribers about errors. Thus, the medical workforce becomes "deskilled". The UK Foundation Programme curriculum sets out the learning outcomes for the first 3 years of medical training after graduation from medical school. ${ }^{9}$ In the section on "safe prescribing", it states that Foundation Year 1 doctors should be able to take an accurate drug history and to prescribe drugs and treatment "appropriately, clearly and unambiguously" and that they are expected to work "closely with pharmacists and more experienced prescribers". ' In a recent review in Scotland of prescribing errors made by medical staff, the majority of junior doctors interviewed were under the impression that their prescribing errors would be picked up by the ward pharmacist. ${ }^{10}$ This might be true during pharmacist working hours, but seldom can the pharmacy provide a 24/7 service, which results in the risk that outside regular working hours, prescribing errors will reach patients. Junior medical staff have to be supported through experiential training to make optimal prescribing decisions and translate these into correctly written prescriptions. 
Finally, in secondary care, multidisciplinary teams with nonmedical prescribers, such as nurses or pharmacists, could also suffer from the syndrome of "too many cooks spoil the broth". I have personally experienced situations in which a medical doctor changed pain medication on the ward round in the morning, with the prescribing pain nurse amending the prescription a mere 2 hours later, with no verbal communication taking place between the prescribers. This results in confusion for the patient and a system with increased potential for errors. Dean and others, ${ }^{11}$ in their program of work on prescribing errors noted, in 2002 (before the introduction of nonmedical prescribing in the UK), that team factors such as poor communication and unclear lines of responsibility are risk factors for prescribing errors. More than a decade later, Ryan and others ${ }^{10}$ found that junior doctors in particular were still confused by the number of individuals and teams that can be involved in prescribing, and team factors remained problematic. These issues will be further increased by adding more prescribers to the mix.

In conclusion, pharmacists are an invaluable resource in any multidisciplinary team in secondary care and are in the best position to advise prescribers about initiation, continuation, or amendments of prescriptions. However, in multidisciplinary teams in hospitals, they are better used as gatekeepers and providers of a safety net for other prescribers, medical and nonmedical, than as prescribers themselves.

\section{References}

1. Cooper RJ, Anderson C, Avery T, Bissell P, Guillaume L, Hutchinson A, et al. Nurse and pharmacist supplementary prescribing in the UK-a thematic review of the literature. Health Policy. 2008;85(3):277-92.

2. Pharmacist prescribing [website]. Edinburgh (Scotland): NHS Education for Scotland; 2014 [cited 2014 Jun 18]. Available from: www.nes. scot.nhs.uk/education-and-training/by-discipline/pharmacy/pharmacists/ pharmacist-prescribing.aspx

3 Tonna AP, Stewart D, West B, McCaig B. Pharmacist prescribing in the UK-a literature review of current practice and research.J Clin Pharm Ther. 2007;32(6):545-56.

4. Crown J. Review of prescribing, supply and administration of medicines: final report. London (UK): Department of Health; 1999 [cited 2014 Jun 25]. Available from: http://webarchive.nationalarchives.gov.uk/+/www.dh.gov.uk/ en/Publicationsandstatistics/Publications/PublicationsPolicyand Guidance/DH_4077151
5. Law MR, Ma T, Fisher J, Sketris IS. Independent pharmacist prescribing in Canada. Can Pharm J. 2012;145(1):17-23.e1.

6. Nissen L. Current status of pharmacist influences on prescribing of medicines. Am J Health Syst Pharm. 2009;66(5 Suppl 3):S529-34.

7. Emmerton L, Marriott J, Bessell T, Nissen L, Dean L. Pharmacists and prescribing rights: review of international developments. J Pharm Pharm Sci. 2005;8(2):217-25.

8. Latter S, Blenkinsopp A, Smith A, Chapman S, Tinelli M, Gerard K, et al. Evaluation of nurse and pharmacist independent prescribing. UK Department of Health Policy Research Programme Project 016 0108. University of Southampton and Keele University; 2010.

9. The Foundation Programme: curriculum and assessment. Cardiff (Wales): UK Foundation Program Office; 2014 [cited 2014 Jun 18]. Available from: www.foundationprogramme.nhs.uk/pages/home/training-and-assessment

10. Ryan C, Ross S, Davey P, Duncan EM, Francis JJ, Fielding A, et al. Prevalence and causes of prescribing errors: the prescribing outcomes for trainee doctors engaged in clinical training (PROTECT) study. PLOS One. 2014;9(1):e79802.

11. Dean B, Schachter M, Vincent C, Barber N. Causes of prescribing errors in hospital inpatients: a prospective study. Lancet. 2002;359(9315): 1373-8.

Yvonne M Hopf, MPharmS, MSc, PhD

Centre of Academic Primary Care

University of Aberdeen

Foresterhill, Aberdeen, Scotland

Dr Hopf is also a teacher practitioner in clinical pharmacy at the hospital of the Ludwig-Maximilians-Universität München (LMU Munich) in Munich, Germany.

Competing interests: Yvonne Hopf has received a National Health Service Applied Programme Grant and a postdoctoral fellowship from the Chief Scientist Office of Scotland for work outside the scope of this article. She is registered as an independent pharmacy prescriber with the General Pharmaceutical Council but does not currently utilize her prescribing rights. Her current post is funded by the Dr August and Dr Anni Lesmüller Foundation. 